fans manually when conditions are appropriate to dry and maintain rice at the desired temperature and moisture content. Alternatively, an aeration controller system can be used to automatically start and stop fans. Our survey shows that aeration controller systems are uncommon. Only one on-farm and eight off-farm operations reported having an aeration controller system.

Grain temperature can be assessed using hand-held thermometers, temperature probes or temperature cables. Hand-held thermometers can measure the temperature of the grain mass surface or of a sample extracted from the grain mass using a grain probe. Temperature probes can be inserted into the grain mass to determine the temperature of the grain at a certain depth. Temperature cables are sensors suspended from the roof of a storage structure that run nearly to the floor of the structure; the number of cables in a structure varies with the structure's size. Temperature probes and cables allow managers to detect grain temperature changes at different grain depths without having to extract samples from these depths. Most of the operations replying to our survey report monitoring grain temperature during storage (see below, "Aeration"). The majority of on-farm operations $(n=23)$ report using a hand-held thermometer $(52.2 \%)$, while most off-farm operations $(n=24)$ report relying on temperature cables within storage structures $(79.2 \%)$.

\section{Storage problems}

Survey respondents were asked to choose and rank the three most important rough rice storage problems they experienced during the past 5 years from a list of six potential problems (fig. 1). For each respondent, the problem ranked as most important, second most important, and third most important received a score of 3,2 and 1, respectively, and problems that were not ranked received a score of 0 . Then, for each problem, the average and relative scores were calculated. A problem's relative score was determined by dividing the problem's average score by the highest possible average score (3). For onfarm operations, maintaining appropriate grain moisture is one of the most important problems respondents faced, followed by insects and grain temperature. For off-farm operations, one of the most

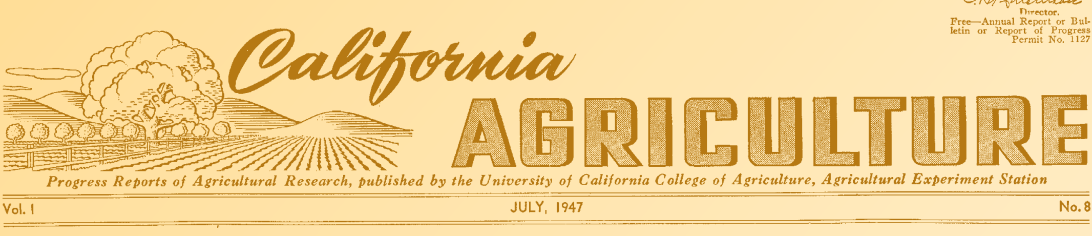

\title{
Early grain storage research
}

1947 "Many insects that infest grain in farm storage are small. Some are smaller than a grain of wheat. In fact, with some species, a single kernel of grain furnishes sufficient food for the development of from one to several individuals.

"Among the more important pests are the granary weevil, rice weevil, lesser grain borer, Angoumois grain moth, confused flour beetle and the sawtoothed grain beetle. The first four mentioned are capable of attacking and destroying sound grain. The others generally feed upon broken grains, particularly the finer particles.

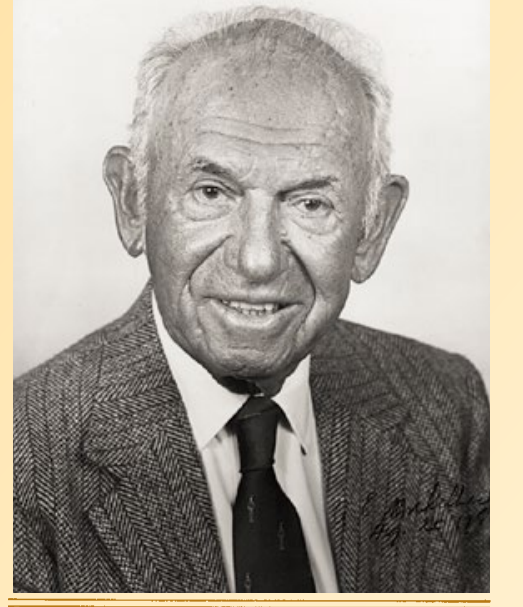

Dryness Protects Farm Stored Grain From Insect Attack

\section{A. E. Michelbacher}

Many insects that infest grain in farm storage are small. Some are smaller than a grain of wheat. In fact, with some species, a single kernel of grain furnishes sufficient food for the development of from one to several individuals.

Among the more important pests are the granary weevil, rice weevil, lesser grain borer, Angoumois grain moth, confused flour beetle and the saw-toothed grain beetle. The first four mentioned are capable of attacking and destroying sound grain. The others generally feed upon broken grains, particularly the finer particles.

Where the environment is favorable, these insects cause serious damage and under extreme conditions the grain may be completely destroyed. Most of the important grain pests are wide-spread throughout California and if grain is not properly protected it is subject to heavy infestation.

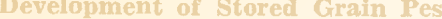

"Where the environment is favorable, these insects cause serious damage and under extreme conditions the grain may be completely destroyed. Most of the important grain pests are widespread throughout California and if grain is not properly protected it is subject to heavy infestation.

"The development of stored grain pests is largely regulated by temperature and the moisture content of the food on which they feed. The most favorable temperature range is from 80 to 85 Deg. F; while the most ideal moisture content of the food ranges from 13 to 17 per cent."

At the time of this writing, author Abraham E. Michelbacher was assistant professor of entomology and assistant entomologist at the Agricultural Experiment Station at UC Berkeley. He went on to become a full professor and leader in UC Berkeley's Department of Entomology, as well as a pioneer in the fields of biological pest control and the specifically targeted use of pesticides. After retirement in 1960, he was named professor emeritus and continued his research and Extension work for nearly 30 years more. Michelbacher died in 1991, aged 92.

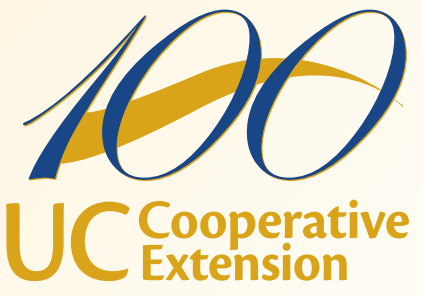

A Celebration of Science and Service 